\title{
CARCAÇA DE BORREGOS ILE DE FRANCE INTEIROS OU CASTRADOS E HAMPSHIRE DOWN CASTRADOS ABATIDOS AOS DOZE MESES DE IDADE
}

\author{
CARCASS OF INTACT OR CASTRATED ILE DE FRANCE AND CASTRATED HAMPSHIRE \\ DOWN LAMBS SLAUGHTERED AT TWELVE MONTHS OF AGE
}

\author{
Edson Luis de Azambuja Ribeiro ${ }^{1}$ Marco Antônio da Rocha ${ }^{2}$ Ivone Yurika Mizubuti \\ Leandro das Dores Ferreira da Silva ${ }^{3}$ Horaci Jaqueline Silva de Souza Ribeiro ${ }^{4}$ Rinaldo Masato Mori $^{5}$
}

RESUMO

Um total de 24 borregos, sendo oito Ile de France inteiros, oito Ile de France castrados e oito Hampshire Down castrados, foram utilizados com o objetivo de avaliar características qualitativas e quantitativas da carcaça. Os animais foram mantidos exclusivamente em pastagem de grama Coast- Cross, sendo abatidos aos 12 meses de idade. As carcaças provenientes de animais inteiros da raça Ile de France apresentaram significativamente maior percentagem de pescoço do que as de animais castrados da mesma raça, sendo essa a única diferença encontrada entre esses dois grupos. Porém, foram observadas diferenças na composição tecidual da paleta entre as raças, sendo que os animais da raça Ile de France (inteiros ou castrados) apresentaram maior percentual de músculo e maior relação músculolosso do que os animais da raça Hampshire Down. Os resultados indicam que, por não haver diferenças importantes entre carcaças e carnes de animais inteiros e castrados abatidos aos 12 meses de idade, o uso da castração pode ser dispensado em sistemas intensivos de produção de carne ovina.

Palavras-chave: abate, carne, composição tecidual, ovinos.

\section{SUMMARY}

A total of 24 lambs, eight intact Ile de France, eight castrated Ile de France and eight castrated Hampshire Down, were used in this experiment with the main objective of evaluating quantitative and qualitative carcass traits. The animals were raised on a Coast-Cross pasture and slaughtered at 12 months of age. Carcasses from intact Ile de France lambs had significantly more neck than carcasses from castrated Ile de France lambs. No other differences were observed between carcasses from intact or castrated Ile de France. However, differences between breeds were observed for tissue composition of the shoulder. Shoulders from Ile de France carcasses (intact or castrated) presented greater percentage of muscles and greater relation of muscles/bones than shoulders from Hampshire Down lambs. Results indicate that intact males can be recommended for sheep meat production systems, when slaughter occurs up to 12 months of age.

Key words: lamb, slaughter, sheep, tissue composition.

\section{INTRODUÇÃO}

A ovinocultura tem grande potencial para aumentar a oferta de proteína animal de alta qualidade, porém, em muitas regiões do país, a atividade é ainda de pouca expressão. Isso se deve basicamente a estrutura de comercialização precária e à qualidade das carnes normalmente oferecidas aos consumidores. Para que a atividade se torne regionalmente importante é necessário, além de melhorar a comercialização, aumentar os índices produtivos e a qualidade do produto oferecido.

Visando a explorar o maior potencial para ganho de peso, bem como carcaças mais magras, tem sido recomendado a utilização de machos inteiros (FIGUEIRÓ \& BENAVIDES, 1990; BEERMANN et $\boldsymbol{a l}$., 1995). Esses benefícios são observados após a puberdade dos animais, que ocorre normalmente entre 6 e 9 meses de idade, dependendo de fatores, tais como fotoperíodo, nutrição e condição corporal (MUKASA-MUGERWA \& EZAZ, 1992; CASTRILLEJO et al., 1995; PRICE et

\footnotetext{
${ }^{1}$ Zootecnista, PhD., Universidade Estadual de Londrina (UEL), Centro de Ciências Agrárias (CCA), Departamento de Zootecnia (DZ), CP 6001, 86051-990, Londrina, PR, Brasil. E-mail: elar@uel.br. Autor para correspondência. 
al., 1995). Em cordeiros com idades de 100 dias (CARVALHO et al., 1999; PIRES et al., 1999) e cinco meses (OSÓRIO et al., 1999), não foram observadas diferenças no desempenho de castrados e inteiros. Porém, com animais um pouco mais velhos (até nove meses) ou mais pesados (pesos de abate entre 54 e 76kg), essas diferenças foram observadas, principalmente no ganho de peso e no teor de gordura corporal (CROUSE $\boldsymbol{e t}$ al., 1981; LLOYD $\boldsymbol{e t}$ al., 1981). Com o avanço da idade ou peso, a carne proveniente de machos inteiros pode apresentar uma diminuição da maciez e de outras características qualitativas. A idade limite para o abate de machos inteiros, sem que a qualidade da carne seja negativamente afetada, depende de vários fatores, tais como peso, sistema de criação e alimentação (LLOYD $\boldsymbol{e} \boldsymbol{t} \boldsymbol{a l}$. , 1981; FIGUEIRÓ \& BENAVIDES, 1990; BEERMANN et al., 1995).

A utilização de raças com maior potencial para ganho de peso, produtoras de carcaças e carnes de melhor qualidade devem ser usadas para melhorar a produtividade e a aceitação por parte do consumidor. Vários trabalhos têm avaliado as diferenças entre raças ovinas (CROSTON et al., 1987; KEMPSTER et al., 1987; PILAR et al., 1994; OLIVEIRA et al., 1996; OSÓRIO et al., 1996; MUNIZ et al., 1997; OLIVEIRA et al., 1998).

Este trabalho teve como objetivos avaliar aspectos produtivos e qualitativos de carcaças e da carne produzida por animais inteiros ou castrados da raça Ile de France, bem como de animais castrados das raças Ile de France e Hampshire Down, quando abatidos aos 12 meses de idade.

\section{MATERIAL E MÉTODOS}

O experimento foi conduzido na Fazenda Escola e Departamento de Zootecnia, do Centro de Ciências Agrárias, da Universidade Estadual de Londrina. Dezesseis borregos da raça Ile de France, sendo oito inteiros (IFI) e oito castrados (IFC), e mais oito borregos Hampshire Down castrados (HDC), foram mantidos em pastagem com grama Coast-Cross (Cynodon dactylon (L.) Pers), dos três aos 12 meses de idade, quando abatidos. Dados de ganho de peso e de componentes do peso vivo, desses animais, foram apresentados por RIBEIRO et al. (2000). Os animais foram pesados antes do abate, após jejum prévio de alimentos sólidos por 18 horas. As carcaças foram pesadas imediatamente após o abate e após refrigeração a $2^{\circ} \mathrm{C}$ por 36 horas em câmara fria.

As medidas tomadas nas carcaças frias baseiam-se nas sugestões de MÜLLER (1980) e
FIGUEIRÓ (1982). Por ocasião da pesagem da carcaça fria, o comprimento de carcaça foi tomado, sendo a distância do bordo anterior do púbis ao bordo anterior medial da primeira costela. As carcaças foram, também, avaliadas subjetivamente para conformação, e foram atribuídos valores de $1=$ muito má a $12=$ muito boa. A compacidade da carcaça foi calculada dividindo-se o peso da carcaça fria pelo seu comprimento. Após as medidas tomadas nas carcaças inteiras, elas foram divididas em perna, paleta, costilhar e pescoço, sendo a perna separada da carcaça na altura do bordo cranial do íleo. O comprimento de perna é a distância entre a extremidade distal inferior da tíbia ao bordo posterior do púbis.

A espessura de gordura subcutânea, média de duas leituras, que recobre o músculo Longissimus dorsi, foi medida entre a $12^{\mathrm{a}}$ e $13^{\mathrm{a}}$ costelas. O contorno do músculo $\boldsymbol{L}$. dorsi foi desenhado em papel vegetal para a determinação da área de olho de lombo em planímetro. $\mathrm{O}$ marmoreio foi avaliado subjetivamente neste músculo, sendo atribuído valores de $1=$ traço a $6=$ abundante. Porções do músculo $\boldsymbol{L}$. dorsi foram retiradas para determinação das características maciez, sabor e suculência, por um painel composto por cinco pessoas. Os valores empregados foram de $1=$ carne extremamente dura, sem suculência ou com sabor desagradável a $9=$ extremamente macia, suculenta ou saborosa.

OLIVEIRA et al. (1998) sugerem que a paleta é uma boa peça para a predição tecidual da carcaça, pois apresenta altos coeficientes de correlação com a composição total da mesma. Dessa maneira, neste trabalho foi avaliada apenas a composição tecidual dessa peça, o que, segundo os autores, citados nos dá uma boa idéia da composição da carcaça como um todo. Através da dissecação da paleta esquerda de cada animal, procedeu-se a separação de músculo, gordura e osso. Além dos pesos e rendimentos de cada componente, observaram-se as relações entre a porção comestível (músculo + gordura) e o peso total da paleta, entre a porção comestível e osso, entre gordura e osso e, entre músculo e osso.

Os dados foram submetidos à análise de variância, tendo como única variável independente a combinação raça-castração (IFI, IFC e HDC). Porém, para as características maciez, suculência e sabor, o modelo incluiu, além do efeito raçacastração, o efeito de amostra dentro de raçacastração, sendo este último efeito usado como erro para testar o efeito principal de raça-castração. A comparação de médias foi feita pelo teste $t$. 


\section{RESULTADOS E DISCUSSÃO}

Médias para as características quantitativas das carcaças são apresentadas na tabela 1 . Não houve diferença $(\mathrm{P}>0,05)$ entre as carcaças dos borregos Ile de France castrados e Hampshire Down castrados para as características quantitativas estudadas. Em diferentes sistemas e condições de criação, CROSTON et al. (1987), KEMPSTER et al. (1987) e MUNIZ et al. (1997) não encontraram diferenças para características quantitativas entre carcaças de animais cruzados das raças Ile de France e Hampshire Down. Carcaças provenientes de machos inteiros da raça Ile de France apresentaram proporcionalmente mais pescoço $(\mathrm{P}<0,05)$ do que carcaças de machos castrados da mesma raça. BEERMANN et al. (1995) comentam que o maior desenvolvimento do pescoço é uma das desvantagens de se utilizar machos inteiros. Em animais com a idade de cinco meses, OSÓRIO et al. (1999), também, observaram uma tendência de maior percentagem de pescoço em animais inteiros. Apesar de não haver diferença estatística $(\mathrm{P}>0,29)$, observou-se que os machos castrados da raça Ile de France apresentaram uma espessura de gordura subcutânea 33,4\% maior do que as carcaças provenientes de machos inteiros. Resultado que está de acordo com as conclusões de FIGUEIRÓ \& BENAVIDES (1990) e BEERMANN et al. (1995). Não houve outras diferenças entre machos inteiros e castrados.

Na tabela 2, são apresentadas as médias para as características qualitativas das carcaças, onde pode-se observar que não houve diferenças estatísticas entre os machos castrados das duas raças, e também entre amostras provenientes de machos inteiros ou castrados da raça Ile de France. FIGUEIRÓ \& BENAVIDES (1990) e BEERMANN et al. (1995) comentam que machos inteiros com

Tabela 1 - Médias para características quantitativas de carcaça de borregos Ile de France inteiros (IFI), Ile de France castrados (IFC) e Hampshire Down castrados (HDC), abatidos aos 12 meses de idade.

\begin{tabular}{lcccc}
\hline \multirow{2}{*}{ Característica } & \multicolumn{3}{c}{ Raça } & \multirow{2}{*}{ PROB.>F } \\
\cline { 2 - 4 } & IFI & IFC & HDC & \\
\hline Carcaça fria, kg & 18,19 & 17,08 & 16,80 & 0,579 \\
Carcaça fria, \% & 47,23 & 47,08 & 45,99 & 0,715 \\
Perna, \% & 33,35 & 35,13 & 34,31 & 0,165 \\
Costilhar, \% & 37,66 & 37,42 & 37,21 & 0,879 \\
Paleta, \% & 18,33 & 18,41 & 18,50 & 0,925 \\
Pescoço, \% & 10,82 a & 9,39 b & 10,05 ab & 0,031 \\
Comprimento carcaça, cm & 59,38 & 57,13 & 59,06 & 0,306 \\
Comprimento de perna, cm & 31,56 & 32,00 & 31,75 & 0,845 \\
Área de olho de lombo, cm ${ }^{2}$ & 12,97 & 12,88 & 11,41 & 0,345 \\
Espessura de gordura subcutânea, mm & 2,81 & 3,75 & 2,31 & 0,294 \\
Compacidade da carcaça, kg/cm & 0,306 & 0,297 & 0,283 & 0,500 \\
\hline
\end{tabular}

a,b - Médias na mesma linha seguidas de letras diferentes, diferem entre si em nível de $5 \%$ de probabilidade pelo teste $t$.
Tabela 2 - Médias para características qualitativas de carcaça e de carne de borregos Ile de France inteiros (IFI), Ile de France castrados (IFC) e Hampshire Down castrados (HDC), abatidos aos 12 meses de idade.

\begin{tabular}{lcccc}
\hline \multirow{2}{*}{ Característica } & \multicolumn{3}{c}{ Raça } & \multirow{2}{*}{ PROB.>F } \\
\cline { 2 - 4 } & IFI & IFC & HDC & \\
\hline Conformação $^{\mathrm{a}}$ & 8,13 & 8,88 & 9,00 & 0,644 \\
Marmoreio $^{\mathrm{b}}$ & 2,00 & 2,38 & 2,25 & 0,531 \\
Maciez $^{c}$ & 5,14 & 5,67 & 5,00 & 0,356 \\
Sabor $^{c}$ & 4,96 & 5,07 & 5,13 & 0,787 \\
Suculência c $^{c}$ & 3,95 & 3,98 & 3,80 & 0,786 \\
\hline
\end{tabular}

${ }^{\text {a }}$ Valores de 1 = muito má a 12 = muito boa.

${ }^{\mathrm{b}}$ Valores de $1=$ traço a $6=$ abundante.

${ }^{c}$ Valores de 1 = extremamente dura, sem suculência ou sem sabor a $9=$ extremamente macia, suculenta ou saborosa.

mais idade ou mais pesados apresentam carnes mais duras, menos suculentas e menos saborosas, e com menor teor de gordura. Os resultados obtidos neste trabalho indicam que até a idade de 12 meses não há um efeito negativo da utilização de machos inteiros. LLOYD et al. (1981), trabalhando com animais abatidos com 54 e $64 \mathrm{~kg}$ de peso vivo, e com idades inferiores a nove meses, também não encontraram diferenças na maciez, sabor e suculência na carne de animais inteiros e castrados.

A composição tecidual e as relações entre componentes da paleta são apresentados na tabela 3 . Verifica-se que não houve diferença estatística para as características da paleta entre animais castrados e inteiros da raça Ile de France. Com animais mais jovens, cinco meses, OSÓRIO et al. (1999), também, não observaram diferenças na composição tecidual da paleta. Porém, em animais com mais idade ou peso, como neste experimento, era de se esperar que carcaças de animais inteiros apresentassem maior percentagem de músculo e menor de gordura (CROUSE et al., 1981; LLOYD et al., 1981). Observou-se que as paletas de animais Ile de France castrados apresentaram maiores proporções de músculo e uma maior relação entre músculo e osso do que paletas de animais castrados Hampshire Down. Houve uma tendência $(\mathrm{P}<0,10)$ das paletas dos animais Hampshire Down apresentarem uma maior proporção de osso e uma menor relação entre a porção comestível (músculo + gordura) e osso. OLIVEIRA et al. (1998), trabalhando com cinco raças, diferentes das usadas neste trabalho, concluíram que o genótipo é importante para explicar diferenças na composição tecidual da paleta. 
Tabela 3 - Médias para composição tecidual da paleta de borregos Ile de France inteiros (IFI), Ile de France castrados (IFC) e Hampshire Down castrados (HDC), abatidos aos 12 meses de idade.

\begin{tabular}{|c|c|c|c|c|}
\hline \multirow[t]{2}{*}{ Característica } & \multicolumn{3}{|c|}{ Raça } & \multirow[t]{2}{*}{ PROB. $>\mathrm{F}$} \\
\hline & IFI & IFC & HDC & \\
\hline Osso, $\mathrm{g}$ & 303,1 & 285,0 & 321,3 & 0,300 \\
\hline Gordura, g & 266,9 & 256,3 & 280,0 & 0,849 \\
\hline Músculo, g & 1030,0 & 844,4 & 900,0 & 0,176 \\
\hline Osso, $\%$ & 19,07 & 19,45 & 21,38 & 0,094 \\
\hline Gordura, \% & 16,41 & 16,54 & 18,79 & 0,342 \\
\hline Músculo, \% & $64,52 \mathrm{~A}$ & $64,01 \mathrm{~A}$ & $59,83 \mathrm{~B}$ & 0,007 \\
\hline Músculo + gordura, \% & 80,93 & 80,55 & 78,62 & 0,095 \\
\hline Músculo / osso & $3,40 \mathrm{a}$ & $3,34 \mathrm{a}$ & $2,83 \mathrm{~b}$ & 0,011 \\
\hline Gordura / osso & 0,88 & 0,87 & 0,89 & 0,992 \\
\hline (Músculo + gordura) / osso & 4,28 & 4,21 & 3,72 & 0,089 \\
\hline
\end{tabular}

A,B - Médias na mesma linha seguidas de letras diferentes, diferem entre si ao nível de $1 \%$ de probabilidade pelo teste $\mathrm{t}$.

a,b - Médias na mesma linha seguidas de letras diferentes, diferem entre si ao nível de $5 \%$ de probabilidade pelo teste $\mathrm{t}$

\section{CONCLUSÕES}

Por não ocorrer diminuição na qualidade da carcaça e carne produzidas, é recomendado a utilização de machos inteiros na produção intensiva de carne ovina, quando o abate ocorre até os doze meses de idade. Borregos da raça Ile de France são superiores aos da raça Hampshire Down, já que os últimos apresentam menor percentagem de músculo na paleta.

\section{REFERÊNCIAS BIBLIOGRÁFICAS}

BEERMANN, D.H., ROBINSON, T.F., HOGUE, D.E. Impact of composition manipulation on lean lamb production in the United States. Journal of Animal Science, v.73, n.8, p.2493-2502, 1995.

CARVALHO, S., PIRES, C.C., PERES, J.R.R., et al. Desempenho de cordeiros machos inteiros, machos castrados e fêmeas, alimentados em confinamento. Ciência Rural, v.29, n.1, p.129-133, 1999

CASTRILLEJO, A., MORANA, A., BIELLI, A., et al. Onset of spermatogenesis in Corriedale ram lambs under extensive rearing conditions in Uruguay. Acta Veterinaria Scandinavica, v.36, n.2, p.161-173, 1995.

CROSTON, D., KEMPSTER, A.J., GUY, D.R., et al. Carcass composition of crossbred lambs by ten sire breeds compared at the same carcass subcutaneous fat proportion. Animal Production, v.44, p.99-106, 1987.

CROUSE, J.D., BUSBOOM, J.R., FIELD, R.A., et al. The effects of breed, diet, sex, location and slaughter weight on lamb growth, carcass composition and meat flavor. Journal of Animal Science, v.53, n.2, p.376-386, 1981.

FIGUEIRÓ, P.R.P. Algumas considerações a respeito da producão de carne ovina. In: SEMANA BRASILEIRA DO CAPRINO, 2, 1978, Sobral, CE. Anais... Sobral EMBRAPA, 1982. 139p. p.43-69.
FIGUEIRÓ, P.R.P., BENAVIDES, M.V. Produção de carne ovina. In: Caprinocultura e ovinocultura. Piracicaba : Sociedade Brasileira de Zootecnia/ FEALQ, 1990. p.15-31.

KEMPSTER, A.J., CROSTON, D., GUY, D.R., et al. Growth and carcass characteristics of crossbred lambs by ten sire breeds, compared at the same estimated carcass subcutaneous fat proportion. Animal Production, v.44, p.83-98, 1987.

LLOYD, W.R SLYTER, A.L. COSTELLO, W.J. Effect of breed, sex and final weight on feedlot performance, carcass characteristics and meat palatability of lambs. Journal of Animal Science, v.51, n.2, p.316-320, 1981.

MUKASA-MUGERWA, E., EZAZ, Z. Relationship of testicular growth and size to age, body weight and onset of puberty in Menz ram lambs. Theriogenology, v.38, n.5, p.979-988, 1992.

MÜLLER, L. Normas para avaliação de carcaças e concurso de carcaças de novilhos. Santa Maria : Imprensa Universitária-UFSM, 1980. 31p.

MUNIZ, E.N., PIRES, C.C., SILVA, J.H.S. DA, et $\boldsymbol{a l}$. Crescimento ponderal e características da carcaça de cordeiros de diferentes genótipos. In: REUNIÃO ANUAL DA SOCIEDADE BRASILEIRA DE ZOOTECNIA, 34, 1997, Juiz de Fora, MG. Anais... Viçosa : SBZ, 1997. v.3, 476p. p.293-295.

OLIVEIRA, N.M., de, OSÓRIO, J.C., MONTEIRO, E.M Produção de carne em ovinos de cinco genótipos. 1. Crescimento e desenvolvimento. Ciência Rural, v.26, n.3, p.467-470, 1996.

OLIVEIRA, N.M., de, OSÓRIO, J.C.S., MONTEIRO, E.M. Produção de carne em ovinos de cinco genótipos. 4. Composição regional e tecidual. Ciência Rural, v.28, n.1, p.125-129, 1998.

OSÓRIO, J.C., OLIVEIRA, N.M. de, NUNES, A.P., et al. Produção de carne em ovinos de cinco genótipos: 3. Perdas e morfologia. Ciência Rural, v.26, n.3, p.477481, 1996.

OSÓRIO, J.C. da S., JARDIM, P.O. da C., PIMENTEL, M.A., et al. Produção de carne entre cordeiros castrados e não castrados. 1. Cruzas Hampshire Down X Corriedale. Ciência Rural, v.29, n.1, p.135-138, 1999.

PILAR, R. de C., PIRES, C.C., RESTLE, J., et al. Desempenho em confinamento e componentes do peso vivo de diferentes genótipos de ovinos abatidos aos doze meses de idade. Ciência Rural, v.24, n.3, p.607-612, 1994.

PIRES, C.C., CARVALHO, S., GRANDI, A., de, et al. Características quantitativas e composição tecidual da carcaça de cordeiros terminados em confinamento. Ciência Rural, v.29, n.3, p.539-543, 1999.

PRICE, E.O., BORGWARDT, R., DALLY, M.R. Heterossexual experience differentially affects the expression of sexual behavior in 6- and 8-month-old ram lambs. Applied Animal Behaviour Science, v.46, n.3/4, p.193-199, 1995.

RIBEIRO, E.L.A., ROCHA, M.A., MIZUBUTI, I.Y., et al. Ganho de peso e componentes do peso vivo em borregos Ile de France inteiros ou castrados e Hampshire Down castrados abatidos aos doze meses de idade. Ciência Rural, v.30, n.2, p.333-336, 2000. 